\title{
Ectopic Scar Pregnancy in a 31-year-old Female with Comorbid: A Case Report and Literature Review
}

\author{
Sanaa Aslam* \\ Shifa College of Medicine, Pakistan
}

Submission: October 10, 2018; Published: October 25, 2018

*Corresponding author: Sanaa Aslam, Shifa College of Medicine, Pakistan, Email: Sanaaaslam95@hotmail.com

Keywords: Ectopic scar pregnancy; Uterine cavity; Caesarean section; Blastocyst implants; Diagnosis; Intrauterine device

\section{Introduction}

An ectopic pregnancy is the implantation of a pregnancy outside the normal uterine cavity. One in 80 pregnancies are ectopic [1]. Caesarean scar ectopic pregnancy is considered the rarest among ectopic pregnancies. It occurs when the blastocyst implants in a previous Caesarean section scar instead of at the usual site in the uterus. It has an estimated incidence of $\sim 1: 1800$ 2200 pregnancies [2,3]. The overall incidence of this rare form of ectopic pregnancies is increasing worldwide. The current incidence of this type of ectopic pregnancies in women with a previous scar is $6 \%$ [4]. The Caesarean section scar can lead to improper healing which makes it more susceptible to implantation. This form of a pregnancy can be life threatening for the mother. In 1978, the first case of a caesarean scar ectopic pregnancy was reported [5]. This form of a pregnancy is usually diagnosed at a gestational age of 5 to 12 weeks [2]. The time interval between the Caesarian section and this type of a pregnancy, on an average, is 6 months to 12 years! [2]. Early diagnosis and recognition of the type of pregnancy can lead to improve in the morbidity and mortality associated with this condition. Prompt treatment leads to fewer complications.

\section{Rationale}

No sufficient documentation is available on the incidence and the prevalence of this form of pregnancy in my country, Pakistan. These forms of literature will further set up grounds for research in this area and hopefully lead to more awareness about the condition

\section{Case Report}

My patient, known case of chronic HTN, came to the OPD with complaints of severe vaginal bleeding for one week. She was sent to the labor room for further assessment. Further history revealed that there was mild PV spotting since the onset of this pregnancy on and off. The bleeding would resolve spontaneously in between, and she sought no medical treatment. Over a duration of one week, the bleeding increased in severity and she would have to change pads 2 to 3 times daily. This was also associated with severe lower abdominal pain, dizziness, lethargy and shortness of breath. A night before her arrival at the hospital, the bleeding intensified, and the blood had then started coming in fist sized clots. She rushed to the hospital. Her past obstetric history revealed 4 previous scars due to cephalopelvic disproportion and 2 miscarriages. She also reported use of copper intrauterine device in the last 3 years. She had well controlled HTN and was on oral medication. Her general physical examination revealed transverse scars, pallor and areas of excessive pigmentation. Her abdominal examination revealed scar tenderness.

On admission, her urine R/E was normal. Blood CBC showed $\mathrm{Hb}$ at $8.30 \mathrm{mg} / \mathrm{dL}$. Her B-HCG was 508.62mIU/mL. Her USG abdomen/ pelvis revealed a large, ill-defined lobula. Heterogeneous mass in the lower anterior segment. An MRI of the pelvis was done which showed an enlarged uterus ( $25 \times 90 \times 80 \mathrm{~mm})$ with an endometrial cavity of $6 \mathrm{~mm}$. A large heterogeneous mass with abnormal signal area. A few high signal foci indicative of hemorrhage and a mass in the myometrium effacing the endometrial cavity at the site of the Caesarean section scar. No bladder involvement. Management decided, at the time, was expectant. Orders to watch for bleeding, Inj. Tranexamic acid $11 \mathrm{gm}$ IV stat and Inj. Methotrexate $1 \mathrm{mg} / \mathrm{kg}$ IM stat were given along with serial B-HCG levels. 6 hours into admission, the patient started bleeding profusely with the passage of massive clots. There were no signs of shock. She was transfused 4 units of PRBCs and given further injections of Tranexamic acid. Her bleeding was controlled 3 hours later. She was taken to the Operative room and Uterine Artery Embolization was performed. Hysterectomy was on hold because of the patient's wish to preserve her fertility.

\section{Discussion}

A scar pregnancy is a life-threatening condition. Early recognition of the disease and prompt management can lead to a much 
better prognosis. These pregnancies have a chance of the development of other morbid conditions like Placenta accreta, placental abruption and other forms of ectopic as well as heterotropic pregnancies.

Patients usually present to the Emergency with painless vaginal bleeding in the first trimester. This bleeding is on and off and can range from mild spotting to the passage of clots associated with heavy bleeding. Proper history and relevant investigations can lead to the diagnosis of ectopic pregnancy and furthermore, scar pregnancies. Initially, a Transvaginal Ultrasound or a color flow Doppler are the modalities of choice. An MRI is performed when the facility is available or in cases when the TVUSS is inconclusive.

Treatment options are many but currently, two major problems exist. The control of bleeding and hemorrhage and the nonviable pregnancy.

For minor bleeding, medical management is sought. Tranexamic acid is an effective agent and is given intravenously as an injectable. IF bleeding is not controlled and blood loss is massive, and the patient is at a risk of hemodynamic instability, consider surgical intervention. Uterine Artery Embolization is now done and is an effective intervention without many complications [6].

For medical management of the pregnancy, systemic methotrexate is given as an injectable according to the body weight of the patient. There has recently been the advent of an ultrasound guided local injection of methotrexate. According to a study published in January 2018 [7], a comparison was made between the efficacy and side effect profile of the local and the systemic methotrexate regimens and it concluded that the local MTX injection treatment may be a better choice for postoperative improvement prognosis and better outcomes than systemic MTX treatment for cesarean section scar pregnancy in combined normal intrauterine pregnancy, in light of adverse effects of MTX on intrauterine pregnancy. The rate of success of local MTX treatment was significantly higher than that of systemic MTX treatment. It was $93.75 \%$ vs. $73.33 \%$, respectively $(\mathrm{P}<0.05)$ [7].
Surgical excision of the scar can also be done which will lead to a lower chance of recurrence and can be considered a key management option [8].

\section{Conclusion}

With the rise in the number of operative deliveries and diagnostic procedures being performed in the modern world, there has also been a rise in the number of ectopic, and more specifically scar pregnancies. Patients with scar pregnancies are considered high risk. Timely diagnosis and serial monitoring are important to prevent any unwanted events and to protect the life of the mother. Reporting of these rare cases is crucial and further research needs to be done in this field.

\section{References}

1. Gynaecology by Ten Teachers $\left(20^{\text {th }} \mathrm{edn}\right)$.

2. Seow KM, Huang LW, Lin YH, Lin MY, Tsai YL, et al. (2004) Cesarean scar pregnancy: issues in management. Ultrasound Obstet Gynecol 23 (3): 247-253.

3. Rotas MA, Haberman S, Levgur M (2006) Cesarean scar ectopic pregnancies: etiology, diagnosis, and management. Obstet Gynecol 107(6): 1373-1381.

4. Dibble EH, Lourenco AP (2016) Imaging Unusual Pregnancy Implantations: Rare Ectopic Pregnancies and More. AJR Am J Roentgenol 207(6): 1380-1392.

5. Larsen JV, Solomon MH (1978) Pregnancy in a uterine scar sacculus: an unusual cause of postabortal haemorrhage. A case report. S Afr Med J 53(4): 142-143.

6. Timor-Tritsch IE, Monteagudo A, Santos R, Tsymbal T, Pineda G, et al. (2012) The diagnosis, treatment, and follow-up of Caesarean scar pregnancy. Am J Obstet Gynecol 207(1): 44e1-44e13.

7. Kim YR, Moon MJ (2018) Ultrasound-guided local injection of methotrexate and systemic intramuscular methotrexate in the treatment of cesarean scar pregnancy. Obstet Gynecol Sci 61(1): 147153.

8. Fylstra DL (2012) Ectopic pregnancy not within the (distal) fallopian tube: aetiology, diagnosis, and treatment. Am J Obstet Gynaecol 206(4): 289-299.

\section{Your next submission with Juniper Publishers will reach you the below assets}

- Quality Editorial service

- Swift Peer Review

- Reprints availability

- E-prints Service

- Manuscript Podcast for convenient understanding

- Global attainment for your research

- Manuscript accessibility in different formats

( Pdf, E-pub, Full Text, Audio)

- Unceasing customer service

Track the below URL for one-step submission https://juniperpublishers.com/online-submission.php 